\title{
The RAND Corporation
}

\author{
A Study of Cartel Stability: The Joint Executive Committee, 1880-1886 \\ Author(s): Robert H. Porter \\ Source: The Bell Journal of Economics, Vol. 14, No. 2 (Autumn, 1983), pp. 301-314 \\ Published by: The RAND Corporation \\ Stable URL: http://www.jstor.org/stable/3003634 \\ Accessed: 01/10/2008 19:09
}

Your use of the JSTOR archive indicates your acceptance of JSTOR's Terms and Conditions of Use, available at http://www.jstor.org/page/info/about/policies/terms.jsp. JSTOR's Terms and Conditions of Use provides, in part, that unless you have obtained prior permission, you may not download an entire issue of a journal or multiple copies of articles, and you may use content in the JSTOR archive only for your personal, non-commercial use.

Please contact the publisher regarding any further use of this work. Publisher contact information may be obtained at http://www.jstor.org/action/showPublisher?publisherCode=rand.

Each copy of any part of a JSTOR transmission must contain the same copyright notice that appears on the screen or printed page of such transmission.

JSTOR is a not-for-profit organization founded in 1995 to build trusted digital archives for scholarship. We work with the scholarly community to preserve their work and the materials they rely upon, and to build a common research platform that promotes the discovery and use of these resources. For more information about JSTOR, please contact support@jstor.org. 


\title{
A study of cartel stability: the Joint Executive Committee, 1880-1886
}

\author{
Robert H. Porter*
}

This article employs weekly time series data on the Joint Executive Committee railroad cartel from 1880 to 1886 to test empirically the proposition that observed prices reflected switches from collusive to noncooperative behavior. An equilibrium model of dynamic oligopoly with asymmetric firms, together with explicit functional form assumptions about costs and demand, determines the estimating equations and stochastic structure of the econometric model. The hypothesis that no switch took place, so that price and quantity movements were solely attributable to exogenous shifts in the demand and cost functions, is then tested against this alternative and rejected.

\section{Introduction}

- Industrial organization economists have recognized for some time that the problem of distinguishing empirically between collusive and noncooperative behavior, in the absence of a "smoking gun," is a difficult one. This article exploits the model proposed in Green and Porter (1984). They consider an explicitly dynamic model in which the firms of an industry are faced with the problem of detecting and deterring cheating on an agreement. In particular, they assume that firms set their own production level and observe the market price, but do not know the quantity produced by any other firm. Firms' output is assumed to be of homogeneous quality, so they face a common market price. If the market demand curve has a stochastic component, an unexpectedly low price may signal either deviations from collusive output levels or a "downward" demand shock. Under these circumstances participating firms can deter deviations from collusive output levels by threatening to produce at Cournot quantities for a period of fixed duration whenever they observe market price below some trigger price. A firm which considers a secret expansion of output above the collusive level must trade off immediate profit gains with the increased probability that the market price will fall below the trigger price, thereby increasing the likelihood of lower profits when the industry reverts to Cournot output levels. Green and Porter offer an explanation that what looks like collusive behavior at a point in time is actually the noncooperative outcome of a regularly repeated market game. For small enough discount rates, an output vector which yields profits in excess of the Cournot vector can be supported as a noncooperative equilibrium. Thus the results of Friedman (1977) and Telser (1972) extend to uncertain environments. In equilibrium, firms maximize expected discounted

* University of Minnesota and Bell Laboratories.

I have benefited from the comments of Tim Bresnahan, Ed Green, Lung-Fei Lee, Richard Quandt, the referees, and the Editorial Board, as well as from the expert research assistance of Rick Hoffbeck and the financial support of a Sloan Foundation Grant to the University of Minnesota Economics Department. I am also indebted to Tom Ulen, who made this data set available to me. An earlier version of this article was presented at the NBER Conference on "The Econometrics of Market Models with Imperfect Competition" at Northwestern University, November 1981 . 
profits by producing at collusive output levels, so that any price wars which are observed should occur after unexpected drops in demand, rather than after actual cheating by member firms. Thus price wars can be the occasional equilibrium outcome of a dynamic noncooperative market game.

There are many such equilibria, as a number of output vectors can be supported by appropriately chosen (trigger price, punishment period length) pairs as noncooperative equilibria. However, such a cartel may be expected to select an enforcement mechanism which maximizes expected discounted profits, subject to the constraint that producing at collusive levels is individually rational. In equilibrium, the marginal gains from cheating in cooperative periods must be exactly offset by the marginal losses implicit in the increased probability of an industry reversion to Cournot behavior. The marginal gains from cheating increase as output in cooperative periods decreases towards perfectly collusive levels, so expected marginal losses must be increased by increasing the trigger price or the length of reversionary episodes. Expected discounted industry profits will be maximized at output levels in cooperative periods which exceed those which maximize singleperiod expected joint net returns, as long as the variance of the demand shock is positive (Porter, 1983).

This article adopts econometric techniques which employ aggregate time series price and quantity data for a particular industry, and which are designed to detect the behavioral switches implied by such an enforcement mechanism. I exploit the fact that there will be periodic switches or reversions between the Cournot and collusive output levels when such a noncooperative equilibrium exists. These reversions serve to identify periods of collusive behavior in a simultaneous equation switching regressions model. There is no explicit test of whether this sort of enforcement mechanism is employed. Instead, the econometric model is designed to test whether significant switches in supplier behavior occurred, and to identify the periods in which they took place. One can then determine whether the pattern of these switches is consistent with an equilibrium of the Green and Porter model. Thus the theoretical model is exploited to the extent that it predicts that such switches will occur, and that they should follow a certain pattern. (Of course, this sort of outcome may also arise if there are external supply shocks which are not observed by the econometrician. I can only state whether the econometric results are consistent with the theoretical model.) The model also predicts that optimally selected output levels in cooperative periods will exceed those which would maximize static joint net returns. The econometric model allows me to determine whether this is in fact the case.

\section{The Joint Executive Committee}

- This section contains a description of the Joint Executive Committee, henceforth referred to as the JEC, with emphasis on the period from 1880 to 1886 . Readers who are interested in a more complete history should refer to MacAvoy (1965) and Ulen (1978). Much of the material in this section is drawn from these studies.

The JEC was a cartel which controlled eastbound freight shipments from Chicago to the Atlantic seaboard in the 1880s. It was formed in April 1879 by an agreement of the railroads involved in the market. The firms involved publicly acknowledged this agreement, as it preceded the passage of the Sherman Act (1890) and the formation of the Interstate Commerce Commission (1887). A separate agreement was reached for westbound shipments on the same railroad lines, primarily because of the essential physical differences of the products being transported.

The internal enforcement mechanism adopted by the JEC was a variant of a trigger price strategy. According to Ulen, there were several instances in which the cartel thought that cheating had occurred, cut prices for a time, and then returned to the collusive price. 
Through-shipments of grain accounted for $73 \%$ of all dead freight tonnage handled by the JEC. The railroads also handled eastbound shipments of flour and provisions, but the prices charged for transporting these commodities were tied to the grain rate. None of these commodities is easily perishable, so speed of delivery was probably not an important factor by which firms could have differentiated their products. Furthermore, while different railroads shipped grain to different port cities, most of the wheat handled by the cartel was subsequently exported overseas, and the rates charged by different firms adjusted to compensate for differences in ocean shipping rates. Thus, the assumption that a homogeneous good was sold seems to have been approximately satisfied, and attention can be focused on the movement of grain with little loss of generality.

Price, rather than quantity, has typically been thought to be the strategic variable of firms in the rail-freight industry. In particular, the specification of Green and Porter (1984) that industry conduct during reversionary periods was Cournot might be considered unrealistic. Econometrically, it is not very difficult to modify the model so that firms revert from collusive to Bertrand behavior (as they would if they were price setters). If firms are price setters, then the inference problem they face in detecting cheating is quite similar to that originally posed by Stigler (1964). In the case of the JEC, the cartel agreement took the form of market share allotments rather than absolute amounts of quantities shipped. Firms set their rates individually, and the JEC office took weekly accounts so that each railroad could see the total amount transported. Total demand was quite variable, and the actual market share of any particular firm depended on both the prices charged by all the firms and unpredictable stochastic forces. Thus, the problem faced by the members of the JEC seems to be comparable to that posed by Green and Porter. Indeed, Brock and Scheinkman (1981) have shown that noncooperative equilibria with similar properties exist in supergames involving price-setting firms which face capacity constraints.

In their model Green and Porter explicitly rule out the possibility of entry into the market. In the case of the JEC, entry occurred twice between 1880 and 1886 . It appears that the cartel passively accepted the entrants, allocated them market shares, and thereby allowed the collusive agreement to continue. The reason for this is undoubtedly that when a firm entered the rail freight industry in the late Nineteenth Century, it faced a "noexit" constraint. To put it briefly, bankrupt railroads were relieved by the courts of most of their fixed costs and instructed to cut prices to increase business (Ulen, 1978, pp. 7074). As a result, I deal with the actual entry which occurred during the sample period by appropriately modifying the nature of collusive and noncooperative outcomes, before and after entry, with the expectation that, ceteris paribus, reversionary periods should not have been precipitated by entry. Of course, entry to the industry may have increased the likelihood of future price wars.

Lake steamers and sailships were the principal source of competition for the railroads, but at no point did they enter into an agreement with the JEC. The predictable fluctuations in demand that resulted from the annual opening and closing of the Great Lakes to shipping did not disrupt industry conduct. Rather, rates adjusted systematically with the lake navigation season.

Therefore, the conduct of the JEC from 1880 to 1886 is largely consistent with the collusive equilibrium described by Green and Porter, as price wars were caused by unpredictable disturbances, rather than by entry or predictable fluctuations in demand.

\section{The econometric model}

- This section is concerned with the possibility of estimating a model of the Nash equilibrium proposed by Green and Porter, suitably altered to reflect the structure of the JEC, by using time series data on price and aggregate output levels. A simultaneous 
equation switching regression model is proposed, in which the parameters of the demand and cost functions are estimated, and in which the regime classification is unknown.

Denote the market price in period $t$ by $p_{t}$. Then the total quantity demanded is assumed to be a loglinear function of price,

$$
\log Q_{t}=\alpha_{0}+\alpha_{1} \log p_{t}+\alpha_{2} L_{t}+U_{1 t},
$$

where $L_{t}$ is a dummy variable equal to one if the Great Lakes were open to navigation, and $\left\{U_{11}, U_{12}, \ldots, U_{1 T}\right\}$ is a sequence of independently distributed normal variables with zero mean and variance $\sigma_{1}^{2}$. Here $\alpha_{1}$ is the price elasticity of demand, and presumably negative. Also $\alpha_{2}$ should be negative, reflecting a decrease in demand when the lake steamers were operating.

The $N$ active firms in the industry are assumed to be asymmetric, in that they each face a different cost function. The cost of producing output $q_{i t}$ for firm $i$ in period $t$ is given by

$$
C_{i}\left(q_{i t}\right)=a_{i} q_{i t}^{\delta}+F_{i}, \quad \text { for } \quad i=1, \ldots, N,
$$

where $\delta$, the (constant) elasticity of variable costs with respect to output, must exceed one if an equilibrium is to exist. Here $a_{i}$ is a firm-specific shift parameter, and $F_{i}$ the fixed cost faced by firm $i$. These fixed costs are assumed to be small enough that firms have positive discounted expected profits in equilibrium.

Since the products provided by these firms are of approximately homogeneous quality, all firms will charge equal prices in equilibrium. The actions of firms under different behavioral assumptions can then be summarized by

$$
p_{t}\left(1+\theta_{i t} / \alpha_{1}\right)=M C_{i}\left(q_{i t}\right) \quad \text { for } \quad i=1, \ldots, N,
$$

where $M C_{i}$ is the marginal cost function of firm $i$. If firms choose price noncooperatively in each period, they price at marginal cost as Bertrand predicted, and so $\theta_{i t}$ equals zero for all $i$ and $t$. If instead they maximize joint profits, $\theta_{i t}$ equals one for all $i$ and $t$. If firms produce at Cournot output levels, $\theta_{i t}$ equals $s_{i t}=q_{i t} / Q_{t}$, the market share of firm $i$ in period $t$.

For estimation purposes, I employ aggregate data. The individual supply equations are weighted by market shares in time $t, s_{i t}$, and added up. Then we get the industry supply relationship

where $\theta_{t}=\Sigma_{i} s_{i t} \theta_{i t}$.

$$
p_{t}\left(1+\theta_{t} / \alpha_{1}\right)=\Sigma_{i} s_{i t} M C_{i}\left(q_{i t}\right)
$$

It can be shown that, given these functional forms for the market demand and cost functions, the market share of firm $i$ in period $t$ will be

$$
s_{i t}=\frac{a_{i}^{1 /(1-\delta)}}{\Sigma_{j} a_{j}^{1 /(1-\delta)}} \equiv s_{i}
$$

in each of the three cases above. Thus the market share of each firm will be constant over time and invariant across changes in industry conduct. Note that the higher the value of the firm-specific variable cost shift parameter, $a_{i}$, the lower is the market share of firm $i$.

The supply relationship can now be written as

where

$$
p_{t}\left(1+\theta_{t} / \alpha_{1}\right)=D Q_{t}^{\delta-1}
$$

$$
D=\delta\left(\Sigma_{i} a_{i}^{1 / 1-\delta}\right)^{1-\delta} .
$$

Note that $D$ depends only on the parameters of the cost functions of the firms. Here $\theta$ equals zero, $H$, or 1 for Bertrand, Cournot, or perfectly collusive firms, respectively. $H$ is the Herfindahl index, $H=\Sigma_{i} s_{i}^{2}$, and is invariant across time, as long as the number 
of firms remains unchanged. Suppose $I_{t}$ is an indicator variable which equals one when the industry is in a cooperative regime and equals zero when the industry witnesses a reversionary episode. Then the supply relationship of the industry is given by

$$
\log p_{t}=\beta_{0}+\beta_{1} \log Q_{t}+\beta_{2} S_{t}+\beta_{3} I_{t}+U_{2 t} .
$$

If reversionary periods are Bertrand, $\beta_{0}=\log D$ and $\beta_{1}=\delta-1$. Since $\delta$ is assumed to be greater than one, $\beta_{1}$ should be positive. Here $S_{t}$ is a vector of structural dummies which reflect entry and acquisitions in the industry. Recall that, for the JEC, entry does not seem to have caused reversions to noncooperative behavior. Then entry should not result in a regime change, only a shift in the parameter $D$. Also, $\left\{U_{21}, \ldots, U_{2 T}\right\}$ is assumed to be a sequence of independent normal variables, with mean zero, variance $\sigma_{2}^{2}$, and $\operatorname{Cov}\left(U_{1 t}, U_{21}\right)=\sigma_{12}$.

If firms behaved in cooperative periods to maximize single-period expected joint net returns, then $\beta_{3}$ would equal $\log \left(\alpha_{1} /\left(1+\alpha_{1}\right)\right)$. However, as I discussed in the introduction, if a cartel selects an optimal trigger price strategy, output in cooperative periods will exceed perfectly collusive levels. While the industry structure described in this article differs from that of Green and Porter, there is some reason to suspect that the same sort of equilibrium will result. To repeat, the larger the profits in cooperative periods, the greater the marginal benefit to secretly cutting price. Then cheating will be deterred only if reversionary periods are of greater length, or more likely to occur. An optimal enforcement mechanism will trade off short-run profits for increased future cartel stability. Thus the value of $\beta_{3}$ will not be restricted, but instead estimated independently. Since market price should be higher in cooperative periods, $\beta_{3}$ should be positive but less than $\log \left(\alpha_{1} /\left(1+\alpha_{1}\right)\right)$.

If the sequence $\left\{I_{1}, \ldots, I_{T}\right\}$ is known, then the estimation of the parameters of the demand and supply functions is straightforward, as two-stage least squares can be employed to obtain consistent estimates. If instead $I_{t}$ is unknown, but assumed to be governed by the Bernoulli distribution

$$
I_{t}=\left\{\begin{array}{l}
1 \text { with probability } \lambda \\
0 \text { with probability } 1-\lambda,
\end{array}\right.
$$

then we have a simultaneous equations switching regression problem, where the "switch" is reflected solely by the constant term in the supply function. The parameters of the demand and supply functions, as well as the switch probability $\lambda$, can be estimated by appropriately generalizing a technique first proposed by Kiefer (1980), which adapts the E-M algorithm to models of this sort.

We can summarize equations (1) and (2) by writing

$$
B y_{t}=\Gamma X_{t}+\Delta I_{t}+U_{t},
$$

where

$$
y_{t}=\left(\begin{array}{c}
\log Q_{t} \\
\log p_{t}
\end{array}\right), \quad X_{t}=\left(\begin{array}{c}
1 \\
L_{t} \\
S_{t}
\end{array}\right), \quad U_{t}=\left(\begin{array}{c}
U_{1 t} \\
U_{2 t}
\end{array}\right)
$$

and where

$$
B=\left(\begin{array}{cc}
1 & -\alpha_{1} \\
-\beta_{1} & 1
\end{array}\right), \quad \Delta=\left(\begin{array}{c}
0 \\
\beta_{3}
\end{array}\right), \quad \text { and } \quad \Gamma=\left(\begin{array}{ccc}
\alpha_{0} & \alpha_{2} & 0 \\
\beta_{0} & 0 & \beta_{2}
\end{array}\right) .
$$

Here $U_{l}$ is identically and independently distributed $N(0, \Sigma)$, where

$$
\Sigma=\left(\begin{array}{ll}
\sigma_{1}^{2} & \sigma_{12} \\
\sigma_{12} & \sigma_{2}^{2}
\end{array}\right) .
$$


The probability density function of $y_{t}$, given $I_{t}$, is then

$$
h\left(y_{t} \mid I_{t}\right)=(2 \pi)^{-1}|\Sigma|^{-1 / 2}\|B\| \exp \left\{-1 / 2\left(B y_{t}-\Gamma X_{t}-\Delta I_{t}\right)^{\prime} \Sigma^{-1}\left(B y_{t}-\Gamma X_{t}-\Delta I_{t}\right)\right\},
$$

and the likelihood function, if there are $T$ observations, is

$$
L\left(I_{1}, \ldots, I_{T}\right)=\prod_{t=1}^{T} h\left(y_{t} \mid I_{t}\right) .
$$

If the $\left\{I_{t}\right\}$ sequence is known, then we can obtain estimates of $B, \Gamma, \Delta$, and $\Sigma$ by maximizing $L\left(I_{1}, \ldots, I_{T}\right)$. When the $\left\{I_{t}\right\}$ series is unknown and governed by equation (3), then the probability density function of $y_{t}$ is given by

$$
\begin{aligned}
f\left(y_{t}\right)=(2 \pi)^{-1}|\Sigma|^{-1 / 2}\|B\| \times\left[\lambda \operatorname { e x p } \left\{-1 / 2\left(B y_{t}\right.\right.\right. & \left.\left.-\Gamma X_{t}-\Delta\right)^{\prime} \Sigma^{-1}\left(B y_{t}-\Gamma X_{t}-\Delta\right)\right\} \\
& \left.+(1-\lambda) \exp \left\{-1 / 2\left(B y_{t}-\Gamma X_{t}\right)^{\prime} \Sigma^{-1}\left(B y_{t}-\Gamma X_{t}\right)\right\}\right]
\end{aligned}
$$

and the likelihood function by

$$
L=\prod_{t=1}^{T} f\left(y_{t}\right)
$$

Given an initial estimate of the regime classification sequence, say $\left\{w_{1}^{0}, \ldots, w_{T}^{0}\right\}$, where $w_{t}^{0}$ is an estimate of $\operatorname{Pr}\left\{I_{t}=1\right\}$, we can obtain an initial estimate of $\lambda$ by using

$$
\lambda^{0}=\Sigma_{t} w_{t}^{0} / T
$$

and initial estimates of $\Delta, \Sigma, B$, and $\Gamma$ by maximizing $L\left(w_{1}^{0}, \ldots, w_{T}^{0}\right)$. Denote these estimates by $\Omega^{0}=\left(\Delta^{0}, \Sigma^{0}, B^{0}, I^{0}\right)$. Kiefer's algorithm then updates the $w_{t}^{0}$ series by Bayes' rule, so that

$$
\begin{aligned}
w_{t}^{1} & =\operatorname{Pr}\left\{I_{t}=1 \mid y_{t}, X_{t}, \Omega^{0}, \lambda^{0}\right\} \\
& =\frac{\lambda^{0} h\left(y_{t} \mid X_{t}, \Omega^{0}, I_{t}=1\right)}{\lambda^{0} h\left(y_{t} \mid X_{t}, \Omega^{0}, I_{t}=1\right)+\left(1-\lambda^{0}\right) h\left(y_{t} \mid X_{t}, \Omega^{0}, I_{t}=0\right)} .
\end{aligned}
$$

Given the new regime classification series $\left\{w_{1}^{1}, \ldots, w_{T}^{1}\right\}$, new estimates of $(\Delta, \Sigma, B, \Gamma)$, say $\Omega^{1}$, can be obtained by maximizing $L\left(w_{1}^{1}, \ldots, w_{T}^{1}\right)$ with respect to $\Omega$. Our new estimates of $\lambda$ will be $\lambda^{1}=\Sigma_{t} w_{t}^{1} / T$. This iterative procedure is continued until convergence occurs, say at $\left(\hat{w}_{1}, \ldots, \hat{w}_{T}\right), \hat{\lambda}=\Sigma_{t} \hat{w}_{l} / T$, and $\hat{\Omega}$. The stopping criterion was that the correlation between the estimated $w_{t}$ sequences of two successive iterations exceed .999 . As Kiefer shows, $\hat{\lambda}$ and $\hat{\Omega}$ will be the maximum likelihood estimates of $\lambda$ and $\Omega$. Thus $\hat{\lambda}$ and $\hat{\Omega}$ maximize the likelihood function $L$ of equation (5). (This is generally true for the E-M algorithm.)

Once estimation is completed, the sample can be classified into collusive and reversionary periods. Lee and Porter (1984) show that if $\hat{w}_{t}$ exceeds .5 , period $t$ should be classified as collusive. This rule minimizes the total probability of misclassification in the sample. Thus, $\left(\hat{w}_{1}, \ldots, \hat{w}_{T}\right)$ generates the classification series $\hat{I}_{t}$, where

$$
\begin{aligned}
\hat{I}_{t} & =1 & & \text { if } \quad \hat{w}_{t}>.5 \\
& =0 & & \text { otherwise. }
\end{aligned}
$$

The Kiefer estimation scheme does not constrain the estimated $\hat{I}_{t}$ series to follow any particular process. If trigger price strategies of the sort described by Green and Porter actually occur, then the $\hat{I}_{t}$ sequence should follow a Markov process of order equal to the length of reversionary periods. Rather than attempt to estimate subject to a constraint of this sort, which would be relatively difficult, I have chosen to employ Kiefer's technique. (Note also that one would expect the duration of reversionary episodes to vary within the sample, as firms solve a new constrained-optimization problem in response to entry.) Green 


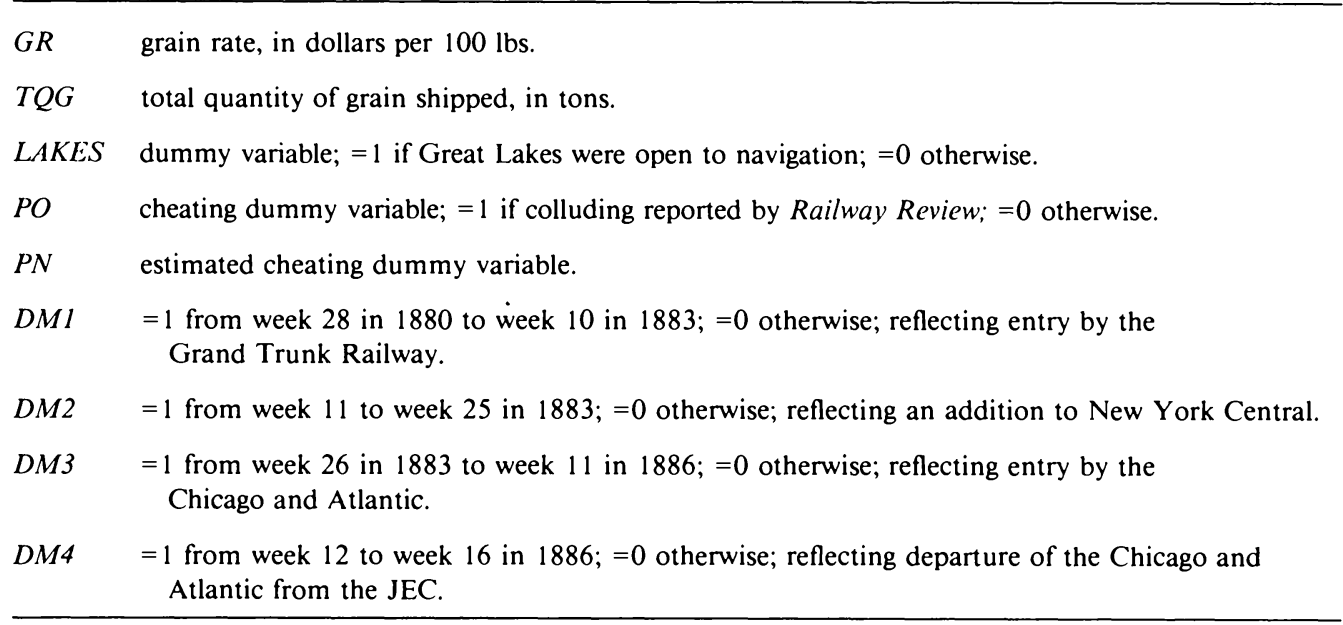

* The sample is from week 1 in 1880 to week 16 in 1886.

and Porter (1984) show that, when the number of reversionary episodes is small relative to the sample size (as is the case for the JEC data), the bias which arises from treating the endogenous Markov process as exogenous will plausibly be slight.

To see how sensitive the estimation scheme is to the specified functional forms, I also estimated the model with a linear specification of equation (4), that is, where $y_{t}^{\prime}=\left[Q_{t}, p_{t}\right]$. These results were not significantly different from those reported in this article, and are documented in Porter (1982).

\section{The data}

A principal function of the JEC was information gathering and dissemination to member firms. Weekly accounts were kept to keep members abreast of developments in the industry. In this section, I document the data set which is employed in this study, and mention some of its features. A list of variables is contained in Table 1. Some summary statistics are provided in Table 2.

The quantity variable, $T Q G$ is the total tonnage of grain shipped by JEC members. It varied dramatically over the sample period, but does not appear to follow any significant trend.

The price variable, $G R$, is somewhat suspect. The JEC polled member firms and provided an index of prices charged. There is some reason to expect that secret price cuts would not be reflected by this index, since there is a moral hazard problem in reporting actual prices. Therefore, any price wars precipitated by secret price cutting may have been recorded with a lag. On the other hand, the existence of this sort of information structure is necessary if an enforcement mechanism involving reversions to noncooperative be-

TABLE 2 Summary Statistics

\begin{tabular}{lcccc}
\hline Variable & Mean & $\begin{array}{c}\text { Standard } \\
\text { Deviation }\end{array}$ & $\begin{array}{c}\text { Minimum } \\
\text { Value }\end{array}$ & $\begin{array}{c}\text { Maximum } \\
\text { Value }\end{array}$ \\
\hline$G R$ & .2465 & .06653 & .125 & .40 \\
$T Q G$ & 25384 & 11632 & 4810 & 76407 \\
LAKES & .5732 & .4954 & 0 & 1 \\
$P O$ & .6189 & .4864 & 0 & 1 \\
\hline
\end{tabular}


havior, or price wars, is to be witnessed. It is of crucial importance that firms monitor some variable (in this case their own market share) which imperfectly reflects the actions of other firms. Here firms knew what prices they charged their own customers, but the $G R$ series would not be of much use in determining whether other firms were secretly cutting price.

While the $L A K E S$ variable documents when the JEC faced its main source of competition, it would be preferable if the prices charged by the lake steamers has also been used in the econometric work. Unfortunately, this series was not available.

The $P O$ series equals one unless the Railway Review, a trade magazine, reported that a price war was occurring. This series concurred with the reports of the Chicago Tribune and other accounts in this period. The $P N$ series is the $\hat{I}_{t}$ sequence, the estimated classification index which indicates whether industry conduct in period $t$ is cooperative, and which should mirror the $P O$ series if the latter is at all accurate. One reason for estimating a $P N$ series is that $P O$, reported by Ulen (1978), conflicts sharply with an index of cartel adherence created by MacAvoy (1965).

The various $D M$ dummy variables proxy structural change caused by entry, departures from the JEC, or additions to existing networks. (In 1886, the Chicago and Atlantic temporarily left the JEC because of a dispute with the railroad which provided them access to the eastern seaboard. This railroad (the Erie) was not a JEC member.) In each case, these changes are presumed to result in a once-and-for-all shift in the constant term of the supply relationship, which is consistent with the algebra of the previous section.

Finally, I also employed dummy variables to capture seasonal aspects of market demand and supply. Each year was segmented into thirteen four-week segments, and so twelve "monthly" dummies entered both the demand and the supply equations.

One assumption of the econometric model of the previous section is that the output shares of JEC members are relatively stable across episodes of reversionary conduct. These shares are allowed to vary when structural change occurs. There are five distinct periods in the sample, as reflected by the $D M$ variables. $D M 1$ and $D M 3$ correspond to the longest periods (281 of 328 sample points), and all reversionary episodes occurred during these intervals. Within these intervals, the average sum (across firms) of squared deviations from allocated market shares was roughly the same in cooperative and reversionary periods. Thus, the assumption of approximately constant market shares seems reasonable, between times of structural change. (This is also borne out by data on the Herfindahl index.) While MacAvoy's (1965) results indicate significant fluctuations from trend shares, he does not examine deviations from allotted shares.

\section{Results and interpretation}

This section contains an interpretive discussion of the econometric results. The regression coefficients obtained when two-stage least squares are applied to the system of equations (4), taking the $P O$ series to be an accurate classification of regimes, are displayed in the left-hand columns of Table 3. Both single equation $R^{2}$ statistics and standard errors of the regression are displayed. Generally speaking, all variables have coefficients of the anticipated sign significantly different from zero, but the "fits" are not particularly good.

In the demand equation the predicted quantity is much lower when the lakes were open. The price elasticity is negative and less than one in absolute value. Thus, the marginal revenue associated with the industry demand curve is negative. This fact is not consistent with single-period profit maximization, which stipulates that industry marginal revenue equal a weighted average of the marginal costs of individual firms, a positive number.

The supply equation is also sensible. Price was significantly higher in cooperative periods. The predicted price of suppliers is an increasing function of quantity shipped, 
but the elasticity is of minor magnitude and only significantly different from zero at a $15 \%$ significance level. Given the presumed cost and demand functions, this might be taken as evidence of weak diseconomies of scale, at least locally. (Of course, these diseconomies might be offset by large fixed costs.) The coefficients of the structural dummies are also reasonable. Entry led to a fall in market price, ceteris paribus, as the coefficient of $D M 1$ is negative, and that of $D M 3$ is less than that of $D M 2$.

The right-hand columns of Table 3 display the results of applying Kiefer's iterative technique. (This algorithm converged to these estimates from several disparate starting points.) The coefficient attributed to $P N$ is the estimate of $\beta_{3}$, i.e., the difference between the intercept of the supply relationship in cooperative and noncooperative periods. The obvious difference between the results of Table 3 is that measures of goodness of fit of the supply equation are dramatically better for the E-M algorithm.

For practical purposes, the demand equations of Table 3 are identical. Again, the demand curve is inelastic. The real differences are reflected in the supply relationships. The coefficient attributed to the $P N$ series, $\beta_{3}$, is larger and with about half the standard error. If we assume that $\beta_{3}=-\log \left(1+\theta / \alpha_{1}\right)$ for some constant $\theta$, then the value of $\theta$ implied by the estimates of $\beta_{3}$ and $\alpha_{1}$ is .336 . This is roughly consistent with Cournot

TABLE 3 Estimation Results*

\begin{tabular}{|c|c|c|c|c|}
\hline \multirow[b]{2}{*}{ Variable } & \multicolumn{2}{|c|}{$\begin{array}{c}\text { Two Stage } \\
\text { Least Squares } \\
\text { (Employing } P O \text { ) }\end{array}$} & \multicolumn{2}{|c|}{$\begin{array}{l}\text { Maximum Likelihood } \\
\quad(\text { Yielding } P N)^{* *}\end{array}$} \\
\hline & Demand & Supply & Demand & Supply \\
\hline$C$ & $\begin{array}{l}9.169 \\
(.184)\end{array}$ & $\begin{array}{c}-3.944 \\
(1.760)\end{array}$ & $\begin{array}{l}9.090 \\
(.149)\end{array}$ & $\begin{array}{r}-2.416 \\
(.710)\end{array}$ \\
\hline$L A K E S$ & $\begin{array}{l}-.437 \\
(.120)\end{array}$ & & $\begin{array}{l}-.430 \\
(.120)\end{array}$ & \\
\hline$G R$ & $\begin{array}{l}-.742 \\
(.121)\end{array}$ & & $\begin{array}{l}-.800 \\
(.091)\end{array}$ & \\
\hline$D M I$ & & $\begin{array}{l}-.201 \\
(.055)\end{array}$ & & $\begin{array}{l}-.165 \\
(.024)\end{array}$ \\
\hline$D M 2$ & & $\begin{array}{l}-.172 \\
(.080)\end{array}$ & & $\begin{array}{r}-.209 \\
(.036)\end{array}$ \\
\hline$D M 3$ & & $\begin{array}{l}-.322 \\
(.064)\end{array}$ & & $\begin{array}{r}-.284 \\
(.027)\end{array}$ \\
\hline$D M 4$ & & $\begin{array}{l}-.208 \\
(.170)\end{array}$ & & $\begin{array}{r}-.298 \\
(.073)\end{array}$ \\
\hline$P O / P N$ & & $\begin{array}{l}.382 \\
(.059)\end{array}$ & & $\begin{array}{l}.545 \\
(.032)\end{array}$ \\
\hline$T Q G$ & & $\begin{array}{l}.251 \\
(.171)\end{array}$ & & $\begin{array}{l}.090 \\
(.068)\end{array}$ \\
\hline$R^{2}$ & .312 & .320 & .307 & .863 \\
\hline$s$ & .398 & .243 & .399 & .109 \\
\hline
\end{tabular}

* Monthly dummy variables are employed. To economize on space, their estimated coefficients are not reported. Estimated standard errors are in parentheses.

** $P N$ is the regime classification series $\left(\hat{I}_{,} \ldots, \hat{I}_{7}\right)$. The coefficient attributed to $P N$ is the estimate of $\beta_{3}$. 
TABLE 4 Price, Quantity, and Total Revenue for Different Values of LAKES and $P N^{*}$

\begin{tabular}{|c|c|c|}
\hline \multirow[t]{2}{*}{ Price } & \multicolumn{2}{|c|}{ LAKES } \\
\hline & 0 & 1 \\
\hline$P N 0$ & . 1673 & .1612 \\
\hline 1 & .2780 & .2679 \\
\hline \multirow[t]{2}{*}{ Quantity } & \multicolumn{2}{|c|}{ LAKES } \\
\hline & 0 & 1 \\
\hline$P N 0$ & 38680 & 25904 \\
\hline 1 & 25775 & 17261 \\
\hline \multirow[t]{2}{*}{ Total Revenue** } & \multicolumn{2}{|c|}{ LAKES } \\
\hline & 0 & 1 \\
\hline$P N 0$ & 129423 & 83514 \\
\hline 1 & 143309 & 92484 \\
\hline $\begin{array}{l}{ }^{*} \text { Computed fro } \\
\text { likelihood estimat } \\
\text { tory variables set } \\
{ }^{* *} \text { Total Reven } \\
\text { dollars per week. }\end{array}$ & $\begin{array}{l}\text { uced form } \\
\text { e } 3 \text {, with } \\
\text { mple mea } \\
\text { Price } \times C\end{array}$ & $\begin{array}{l}\text { ximum } \\
\text { xplana- } \\
\text { to yield }\end{array}$ \\
\hline
\end{tabular}

behavior in cooperative periods. The witnessing of approximately Cournot behavior is by itself of no special significance. What matters is that cooperative period prices exceed those implied by competitive price setting, but are less than those consistent with static joint profit maximizing, as predicted by Porter (1983).

If we set all explanatory variables equal to their sample mean, with the exception of the $L A K E S$ and $P N$ dummy variables, then the maximum likelihood estimates displayed in Table 3 imply the reduced-form estimates shown in Table 4 . Thus, in equilibrium, price was $66 \%$ higher in cooperative periods, and quantity $33 \%$ lower. Similarly, price was $4.5 \%$ lower when the lakes were open, and quantity $33 \%$ lower. The total revenue figure is twenty times the product of $G R$ and $T Q G$, and so in dollars $(20 \times \$$ per $100 \mathrm{lbs}$. $X$ tons). Thus, the cartel as a whole could expect to earn $11 \%$ higher revenues in cooperative periods, a difference of about $\$ 11,000$ per week. (Recall that these are 1880 dollars.) This is the revenue earned on grain shipments, which represented between 70 and $80 \%$ of total revenues from eastbound freight shipments by the JEC. Finally, revenues were about $35 \%$ lower when the lakes were navigable.

The $P O$ and $P N$ series are depicted, together with $G R$, in Figure 1, which shows when noncooperative episodes were predicted by the two series. Both series are similar to the extent that noncooperative periods averaged about 10 weeks in duration, and primarily occurred in 1881,1884 , and 1885 . In several instances, $P O$ reflects a price war before $P N$, and both switch back to unity together, which is consistent with $G R$ not picking up secret price cuts. For either series, a regression of price war length on the realization of the demand equation residual error term in the period before the beginning of the episode had little predictive power. Of course, the demand equation is marred by a missing variable problem (namely, the price charged by lake steamers), so there is not much reason to think that the demand residuals would accurately reflect unexpected disturbances. (Some people have suggested that optimal price war length might depend on the magnitude of the demand shock.) More importantly, since JEC firms were price setters, price wars may not have necessarily been triggered by adverse demand shocks. 
FIGURE 1

PLOT OF GR, PO, PN AS A FUNCTION OF TIME

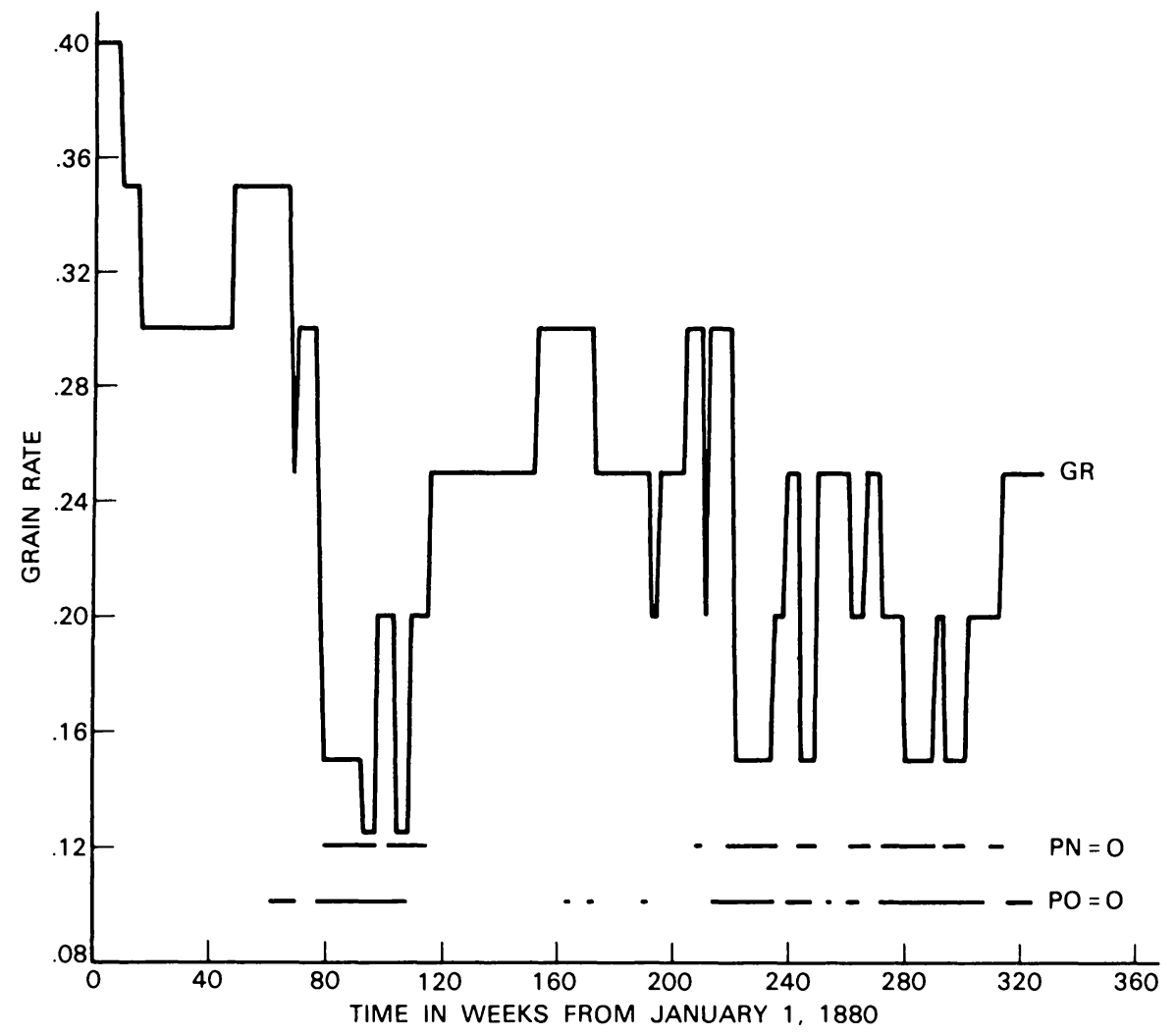

As predicted by Stigler (1964), unpredictable fluctuations in market shares were probably more decisive. In this sample, price wars (as measured by either $P O$ or $P N$ ) were not preceded by large negative demand residuals.

The 1881 and 1884 incidents both began about 40 weeks after the entry of the Grand Trunk and the Chicago and Atlantic, respectively. While entry may not have immediately caused reversion to noncooperative behavior, it is quite plausible that it increased the probability of its incidence in the future, as cartel enforcement problems typically increase with the number of participating firms. In the sample, reversions were more frequent when the number of firms increased. (They were also shorter, on average.)

The $P O$ series collected by Ulen (1978) differs markedly from an index of cartel nonadherence created by MacAvoy (1965). These series, as well as $P N$, are summarized in Table 5. The "Reported" and "Estimated" columns show the fraction of weeks in each year in which $P O$ and $P N$ were equal to zero, respectively. Since the $P N$ series was in no way constrained to resemble $P O$, it is evident that $P N$ supports the documentation of the Railway Review and Chicago Tribune, rather than MacAvoy's results.

To conclude this section, I consider the statistical evidence that switches actually occurred and were significant. First, the coefficient of $P O$ and that attributed to $P N$ are significantly greater than zero, so that periods of cooperation involved a significantly higher price.

Likelihood ratio tests can be used to determine whether structural change has in fact occurred. The natural null hypothesis to be tested is that only cooperative or noncooperative behavior is observed, but not both. These are the respective implications of the equilibria described by Friedman (1977) and Telser (1972), or of a Nash open-loop strategy 
TABLE 5 Index of Cartel Nonadherence ${ }^{1}$

\begin{tabular}{lccc}
\hline Year & MacAvoy $^{2}$ & Reported $^{3}$ & Estimated $^{4}$ \\
\hline 1880 & 26 & 0.00 & 0.00 \\
1881 & 14 & 0.67 & 0.44 \\
1882 & 18 & 0.06 & 0.21 \\
1883 & 6 & 0.10 & 0.00 \\
1884 & 16 & 0.58 & 0.40 \\
1885 & 10 & 0.77 & 0.67 \\
$1886^{5}$ & 15 & 0.50 & 0.06 \\
\hline
\end{tabular}

\footnotetext{
'Columns 1 and 2 are taken from Ulen (1978, p. 336).

${ }^{2}$ The number of months, summed over all cartel members, for which the difference between the actual market share and "trend" share of tonnage was greater than the standard error from the "trend" share regression of each member road. The greater this number of months, the less stable the cartel is likely to be.

${ }^{3}$ For year $i$, this index is $\Sigma(1-P O(t)) / 52$, where the summation is over $t$ in year $i$.

${ }^{4}$ This index is $\Sigma\left(1-\hat{I}_{t}\right) / 52$, summing over $t$ in year $i$.

${ }^{5} P O$ and $P N$ only exist for the first 16 weeks, so the denominator of the indices is 16 rather than 52 .
}

equilibrium. The value of the likelihood function, given the Kiefer estimation technique, can be compared to that when $L$ is maximized subject to the constraint that $\Delta=0$.

Suppose that $L_{1}$ is the maximized value of the log likelihood function for the specification of Table 3 when Kiefer's technique is used, and $\left(\hat{B}_{1}, \hat{\Sigma}_{1}\right)$ the corresponding estimates of $(B, \Sigma)$. Further, suppose that $L_{0}$ is the maximized value of the log likelihood function for this specification when $\Delta$ equals zero, and that $\left(\hat{B}_{0}, \hat{\Sigma}_{0}\right)$ are the estimates of $(B, \Sigma)$. Then

$$
L_{1}-L_{0}=\left(\log \left\|\hat{B}_{1}\right\|-1 / 2 \log \left|\hat{\Sigma}_{1}\right|\right)-\left(\log \left\|\hat{B}_{0}\right\|-1 / 2 \log \left|\hat{\Sigma}_{0}\right|\right) .
$$

Under the null hypothesis that no regime change is observed, $2 T\left(L_{1}-L_{0}\right)$ has a chisquared distribution with one degree of freedom. For the JEC sample, $2 T\left(L_{1}-L_{0}\right)$ is 554.1. Thus I can overwhelmingly reject the hypothesis that no switch occurred, given the specifications adopted. Price and quantity changes cannot be attributed solely to exogenous changes in demand and structural conditions. The similarity of the estimated $P N$ series and the $P O$ series indicate that some price changes can be attributed to periods of noncooperative behavior, and that the incidence of alleged switches in behavior cannot be explained by missing data problems.

The conclusions of this section are quite robust, as they are obtained under a variety of different specifications and functional forms.

\section{Summary}

The econometric evidence presented in the previous section indicates that reversions to noncooperative behavior did occur in the JEC, with a significant decrease in market price in these periods. The econometric results indicating that these episodes were concentrated in 1881,1884 , and 1885 are in keeping with the behavior of the JEC that was reported at that time. The question remaining, however, is what the causes of these reversions were. 
TABLE 6 Annual Eastbound Shipments of Wheat

from Chicago by Lake and Rail*

\begin{tabular}{cccccc}
\hline Year & \multicolumn{2}{c}{ Lake } & \multicolumn{2}{c}{ Rail } & $\begin{array}{c}\text { Total } \\
\text { Shipments }\end{array}$ \\
\hline & Total & Percentage & Total & Percentage & \\
1880 & 16.69 & 77.9 & 4.728 & 22.1 & 21.42 \\
1881 & 7.688 & 50.0 & 7.680 & 50.0 & 15.37 \\
1882 & 14.94 & 86.2 & 2.389 & 13.8 & 17.33 \\
1883 & 7.067 & 73.2 & 2.590 & 26.8 & 9.66 \\
1884 & 11.52 & 66.0 & 5.928 & 34.0 & 17.45 \\
1885 & 5.436 & 51.5 & 5.116 & 48.5 & 10.55 \\
1886 & 10.51 & 82.6 & 2.209 & 17.4 & 12.72 \\
\hline
\end{tabular}

* in millions of bushels.

Traditionally, breakdowns in cartel discipline have been attributed to demand slumps, both within the JEC as well as in other cartels. What distinguishes the theoretical model of Green and Porter (1984) from other theories of cartel stability is that reversionary episodes, or price wars, are caused by an unanticipated change in demand, in this case reflected by an unusually low market share for at least one firm, rather than by a prolonged drop in total market demand. Trying to determine which model best describes the observed behavior of the JEC from 1880 to 1886 is not an easy task, but I can refer to two pieces of evidence which may support the Green and Porter paradigm. First, the reduced-form estimates predict that price was lower and quantity higher in reversionary periods, ceteris paribus. Of course, this could merely reflect the fact that demand was quite elastic with respect to price changes, a fact at least partially refuted by the estimated price elasticity of demand. Second, one can look at total grain shipments from Chicago to see what fraction is accounted for by the JEC. Annual data showing the amount of grain shipped by lake steamers versus railroads are presented in Table 6. Of the years in the sample, 1880 is a boom year, which would account for the unusually high prices charged then. Of the remaining years, the annual variation in total shipments is not correlated with measures of cartel nonadherence. The distinguishing feature of the "breakdown" years of 1881, 1884, and 1885 is the much higher market share captured by the JEC as a whole in the intermodal competition to ship wheat. This is an indication that JEC price wars were not concurrent with lake steamer price wars, and also that JEC price wars did not always occur in years when total demand was unusually low. Thus, while some observers have claimed that price wars will be triggered by the unexpected tapering off of demand, which is consistent with the paradigm of Green and Porter, the JEC seems to be a case where this was not necessarily true of periods in which demand was low per se. Further support of this contention is that the $P O$ and $P N$ series are not systematically related to the opening or closing of the lake steamer shipping season. Finally, the fact that the frequency of reversionary periods increased as the number of market participants increased is consistent with a story of dynamic cartel enforcement mechanisms, especially since the "no-exit" constraint faced by railroads deterred predatory reactions to entry.

\section{References}

Brock, W.A. ANd Scheinkman, J.A. "Price-Setting Supergames with Capacity Constraints." SSRI Paper No. 8130, University of Wisconsin-Madison, 1981.

Friedman, J.W. Oligopoly and the Theory of Games. Amsterdam: North-Holland, 1977. 


\section{4 / THE BELL JOURNAL OF ECONOMICS}

GREen, E.J. AND PORTER, R.H. "Noncooperative Collusion under Imperfect Price Information." Econometrica, Vol. 52 (January 1984).

KIEFER, N.M. “A Note on Switching Regressions and Logistic Discrimination." Econometrica, Vol. 48 (May 1980), pp. 1065-1069.

LEE, L.F. AND PORTER, R.H. "Switching Regression Models with Imperfect Sample Separation InformationWith an Application on Cartel Stability." Econometrica, Vol. 52 (January 1984).

MacAvor, P.W. The Economic Effects of Regulation. Cambridge: M.I.T. Press, 1965.

PORTER, R.H. "A Study of Cartel Stability: The Joint Executive Committee, 1880-1886." C.E.R. Discussion Paper No. 82-158, University of Minnesota, 1982.

$\rightarrow-$. "Optimal Cartel Trigger Price Strategies." Journal of Economic Theory, Vol. 29 (April 1983), pp. 313338.

Stigler, G.J. “A Theory of Oligopoly.” Journal of Political Economy, Vol. 72 (February 1964), pp. 44-61. TElSER, L.G. Competition, Collusion, and Game Theory. Chicago: Aldine-Atherton, 1972.

UlEN, T.S. Cartels and Regulation. Unpublished Ph.D. dissertation, Stanford University, 1978. 